\title{
Community Living Lab as a Collaborative Innovation Environment
}

\author{
Jacobus S. van der Walt and Albertus A.K. Buitendag \\ Tshwane University of Technology, Pretoria, Gauteng, South Africa \\ vanderWaltJS@tut.ac.za, BuitendagAAK@tut.ac.za \\ Jan J. Zaaiman \\ University of Venda, Thohoyandou, Limpopo, South Africa \\ Jannie.zaaiman@univen.ac.za \\ J. C. Jansen van Vuuren \\ CSIR, Pretoria, Gauteng, South Africa \\ ijvuuren@csir.co.za
}

\begin{abstract}
A Living Lab is a new way to deal with community-driven innovation in real-life contexts. The Living Lab concept is fuelled by knowledge sharing, collaboration and experimenting in open real environments. This research explores the sustainable development of community Living Labs within a South African context. The members of rural communities need sustainable development support in order to create jobs and alleviate poverty. In order to do so they need an open multidisc iplinary research and systems thinking support environment which is facilitated in the Living Lab environment. The Living Lab approach provides its user group with an opportunity to develop a much deeper understanding of how the various components in their functional environment operate and interrelate. In the research community the Living Lab concept seems to be gaining increasing acceptance as a way to deal with innovation and to get insight into the innovation process. Several Living Labs are currently connected in a network of Living Labs, both in Europe and in South Africa aiming to share best practices and lessons learned. Creating an innovative software based management model for Living Labs for the greater South African region is also part of the research objectives. This paper presents two interrelated frameworks for the establishment of a Living Lab within a South African context. The paper also highlights the important role of holistic Systems thinking in a Living Lab environment.
\end{abstract}

Material published as part of this publication, either on-line or in print, is copyrighted by the Informing Science Institute. Permission to make digital or paper copy of part or all of these works for personal or classroom use is granted without fee provided that the copies are not made or distributed for profit or commercial advantage AND that copies 1) bear this notice in full and 2) give the full citation on the first page. It is permissible to abstract these works so long as credit is given. To copy in all other cases or to republish or to post on a server or to redistribute to lists requires specific permission and payment of a fee. Contact Publisher@InformingScience.org to request redistribution permission.
Keywords: Living labs, Value Chains, Collaboration, Systems Thinking

\section{Introduction}

Many private and public investments in community development fail to produce real and sustaining value for communities. Some of the deficiencies observed are that traditional community development projects are initiated and executed 
in a closed and artificial laboratory environment with limited interaction with, and understanding of the real needs, the potential problems and value chains of the community.

To effectively design world class sustainable and prosperous communities, new powerful innovation approaches are urgently needed. The approach suggested in this paper, is to build collaborative systems, called Living Labs (LL), for communities which will engage and empower them to experiment and learn in real-world environments and to create innovative solutions to the ir problems.

From an educational perspective the role and important impact of implemented living labs are becoming more evident. Van der Walt \& Pretorius (2007) opened an article entitled: Living Lab as an Innovative Tool in Education by explaining that: Today's ICT learning environments are ventures involving huge streams of course material development, knowledge transfer, and performance measuring systems. The service delivery of many organizations depends on the functioning of these skills production / chains of the academic institutions. This skills production process requires the marketing of students, optimal use of teaching resources and performance analysis. Performance analysis is a complete process and depends on value adding, processes of many role players. Understanding the bus iness, technology and social intersection of the learning environment is critical for the successful analys is of skills requirement.

We believe that one of the best tools to promote highly innovative action research in different application areas is through the use of "living labs". Living labs is a highly evolving theory and practice, related to almost any managerial or technical problem, which can be used to help organizations in knowing where to focus their management attention. According to CoreLabs/ENoLL, (2007:3) a Living Lab enables users to take active part in research and innovation.

\section{Living Labs}

The following section presents various views and definitions from literature in order to clarify and explain the researched topic. In the latter part the researchers aim to provide a working definition for a living lab in the South African context with reference to the envisaged Soshanguve and Venda Living Lab Projects.

\section{Living Labs Defined}

Pallot (2006) argues that a "living lab" (LL) is neither a traditional research lab nor a "testbed", but rather an "innovation platform" that brings together and involve, or in stronger words, engage all stakeholders such as end-users, researchers, industrialists, policy makers, and so on at the earlier stage of the innovation process in order to experiment breakthrough concepts and potential value for both the society (citizens) and users that will lead to breakthrough innovations. A European Network of Living Labs, ENoLL, has been established (Nov. 2006) and comprises (Nov. 2007) 52 Living Labs in eighteen of the twenty five European Union member states. European Network of Living Labs (2006, p. 1) define living labs as: "The Living Lab is a system and environment for building a future economy in which real-life user-centric innovation will be the normal co-creation technique for new products, services and societal infrastructures."

Lama and Origin (2006, p. 6) describe living labs as "a user-centric research methodology for sensing, prototyping, validating and refining complex solutions in multiple and evolving real life contexts."

Living labs challenge us to examine new technologies in everyday contexts as used by people to achieve their goals. In this context, people from different areas of life explore innovative tools by interacting with them and discovering new ideas to expand their knowledge and to explore ways of acting (Lacasa, Martinez, Mendez, \& Cortes, 2007, p. 2). 
Living labs are getting momentum especially in developing communities; the driving force being resource-sharing capabilities coupled with technology advancement demanding extensive infrastructure that is not easy to acquire. This is especially true for small and medium enterprises and those who need high technology to achieve their goals. There is a reduction of technology and business risks, and the large companies have a large pool of ideas to help in their ventures (Lama \& Origin, 2006, pp. 5-10).

According to Boronowsky, Herzog, Knackfub, and Lawo (2006) a living lab is more than a digital breeding area; it is a constructed setting of technology, shared by various researchers sharing the same drive, focused on finding the results and helping one another to achieve their goals. Researchers within living labs are restricted to monitoring from the inside what is going on. On the other hand, researchers are part of a living lab and have the capabilities to intervene in order to contribute to a better implementation of technological innovation in social practices, and deal with the unpredictable processes by reflecting on and consequently adjusting the ir own methodology. (Boronowsky et al., 2006).

There is a growing industrial need for user-driven innovation and 'living-labbing' in an array of industries. Producer centred innovation is being eclipsed by user-driven innovation - the idea generation, concept development, prototyping, and even production of new products and services is done by users/consumers. These users aren't just voic ing their needs to companies that are willing to listen; they're inventing and often building what they want. (CoreLabs, 2007)

All these new technological capabilities converge broadly at the Workplace (Dynamic Workplace, Collaborative Workplace). This is where the Knowledge Worker of 21st century is enabled to perform the knowledge work in a productive way. Given the increasing need to mobilize the "collective intelligence and creativity" collaborative technologies will be vital - not only for the individual know ledge worker but for business and the society at large.

All Living Labs share the human-centric involvement and its potential for development of new ICT-based services and products. This is done by assembling different stakeholders in a cocreative way.

From an educational perspective the UNC (2007) stated that "A Living Lab could also be seen as a regular university space - such as a classroom or conference room - that serves as a staging area for technologies under assessment."

From the various definitions it is obvious that there are two different streams of thoughts regarding the LL concept. Some definitions see are of the opinion that a LL is a pure "testbed" for innovative solutions while the other see a living labs as a pure means to conduct context research and co-creation with other users.

Følstad (2008, p. 119) explained that Living Lab literature has served to identify two aspects that may be used to discriminate between the Living Labs that comply with the general definition:

- Contextualized co-creation: Living Labs supporting context research and co-creation with users

- Testbed association: Living Labs serving as a testbed extension, where testbed applications are accessed in contexts familiar to the users.

\section{Living Lab Thinking Framework}

The main objective of the LL is to create prosperous communities. Many critical success factors for prosperous communities are stated in research papers, but the ones mentioned most of the time is connected to trust, involvement of members in the innovation process, access to adequate knowledge regarding the problem environment, state-of-the-art ICT tools and methodologies, and 
good governance. A LL supports core research capabilities and shared understanding in order to learn and understand complexity. The Community LL framework is based on systems thinking grounding as presented in Figure 1.

Thinking is a process of figuring things out, knowing why and how things work. The framework presented provides the researchers perspectives of the various thinking activities and processes for a Living Lab. A LL can be seen as thinking and rethinking support environments, connected to generic decision making (intelligence, design, choice and implementation) and action research (sense learn, act) processes. Simply put, a LL framework based on thinking as depicted in Figure 1 can function as a springboard to prosperous communities to build entrepreneurial capacities and achieve sustainable continuous improvement.

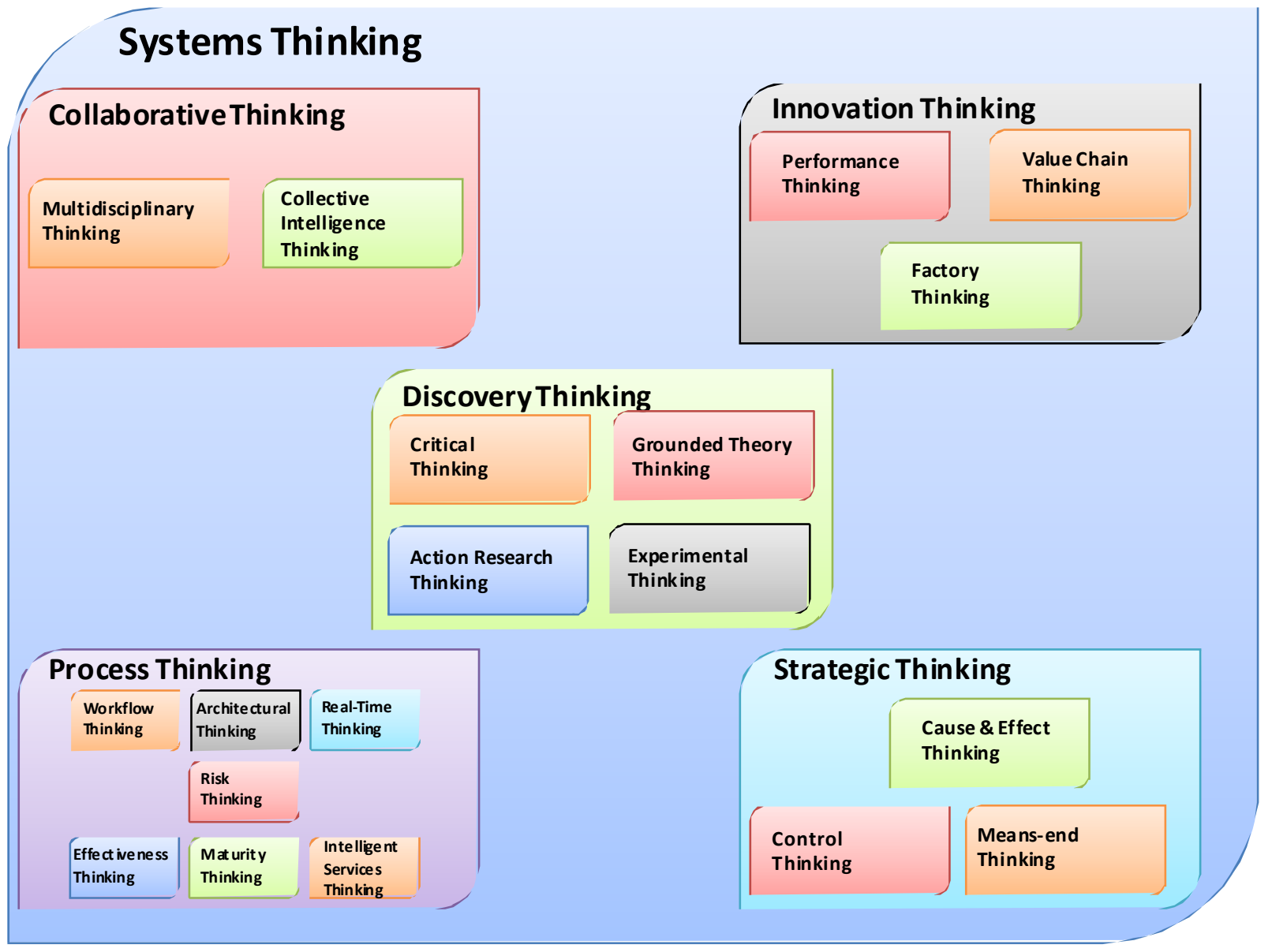

Figure 1: Living Lab Thinking Frame work

According to SystemsThinking.org (2009) systems thinking is, more than anything else, a mindset for understanding how things work. It is a perspective for going beyond events, to looking for patterns of behavior, to seeking underlying systemic interrelationships which are responsible for the patterns of behavior and the events. Systems thinking embody a world-view. A world-view which implies that the foundation for understanding lies in interpreting interrelationships within systems. Interrelationships which are responsible for the manner in which systems operate. Interrelationships which result in the patterns of behavior and events we perceive. 
Systems thinking in this context advocates collaborative, innovation, discovery, strategic and process thinking. Collaboration thinking is supported by multidisciplinary and collective intelligence thinking. Innovation thinking is supported by performance, value chain and factory thinking.

Innovative thinking is linked to creative thinking and problem solving; generate something new or find new ways to solve problems. According to squidoo.com, brainstorming.co.uk, innovation.cc and others, innovation thinking means having to answer simple questions such as: What makes an idea a good idea? How do you consistently generate good ideas? How do you find that magic 'x factor' that makes an idea stand out? How can I be more creative and inventive? What do I do with my ideas? Where do I go to solve my problems? How do I look for opportunities to innovate? If I think I have found an opportunity, how do I capitalize on it? How do I get my opportunity implemented? What resources are available to help me innovate? What ideas do you believe to be creative? Who do you consider to be creative?

Simply put, performance thinking helps organizations achieve their strategic goals. Performance thinking is the process of assessing progress toward achieving predetermined goals. Performance management is building on that process, adding the relevant communication and action on the progress achieved against these predetermined.

The main purpose of performance thinking is to link performance objectives and organizational strategies to increase profit. A performance problem is any gap between desired results and actual results. Performance improvement is any effort targeted at closing the gap between actual results and desired results. Thompson, Strickland, and Gamble (2007, p. 555) make the statement, "As significant as the strategy to performance gap is at most companies, management can close it. They can work on both sides of the equation, raising standards for both planning and execution simultaneously."

The process starts with grounded theory thinking, identify and analyze key issues and find all the role players and create partnerships, using a bottom up collaborative thinking approach. The next process use value chain thinking to analyze and brainstorm the value chains.

Value chain thinking is the interdisciplinary process of determining what the full range of activities is to release a product or service to the market. In order to reduce the cost and improve the economic value of these activities throughout the value chain, promoting innovation and cooperation.

Discovery thinking is supported by critical, grounded theory, action research and experimental research thinking. This thinking process stimulate innovation by finding patterns in data, events, design processes, research processes decision making. These patterns are transformed into knowledge and best practices in order to enhance human cognition and deriving fundamental insight into complex problems and systems. The discovery process is supported by analytical and critical thinking research processes.

Critical thinking is the means and ends of learning. The critical thinker should remain open to new ideas and think like a scientist, applying skeptic ism to ways of doing things; use and create his/her own information and reject information that is irrelevant and faulty; state his/her own arguments; come to his/her own conclusions; listen to other peoples and tolerate their thinking.

Process thinking is supported by workflow, architectural, real time, risk, effectiveness, maturity and intelligent services thinking. Process thinking, focus on identification, understanding, design and management of processes. Work is performed by activities and related activities form workflows and are managed as an objective integrated system. The majority of the problems in systems are connected to bad processes and not to people, that's why process thinking must ensure that the needed processes are in place. Work smarter and not harder by improving the processes 
and don't place the blame on people. Process thinking is supported by workflow, architectural, real time, risk, effectiveness, maturity and intelligent services thinking.

Strategy thinking is a way of thinking about changes and preparing for them. Strategic thinking should be seen as a process to help an organization confront change, analyze its impact and look for new opportunities. Strategic thinking is supported by sustainability thinking, objective thinking and means ends thinking.

\section{Living Lab Framework}

The previous section introduced the living lab concept, providing definitions of a living lab as well as discussing the LL thinking framework. In this section, a proposed framework for a living lab for meat quality assurance is introduced. The incorporation of a quality factory in a living lab has advantages in terms of resource sharing, as well as creative and innovative thinking. The best method of innovative thinking is to encourage collaboration and information sharing; to share experiences and successes with enthusiastic researchers learning from the success and failures of their counterparts.

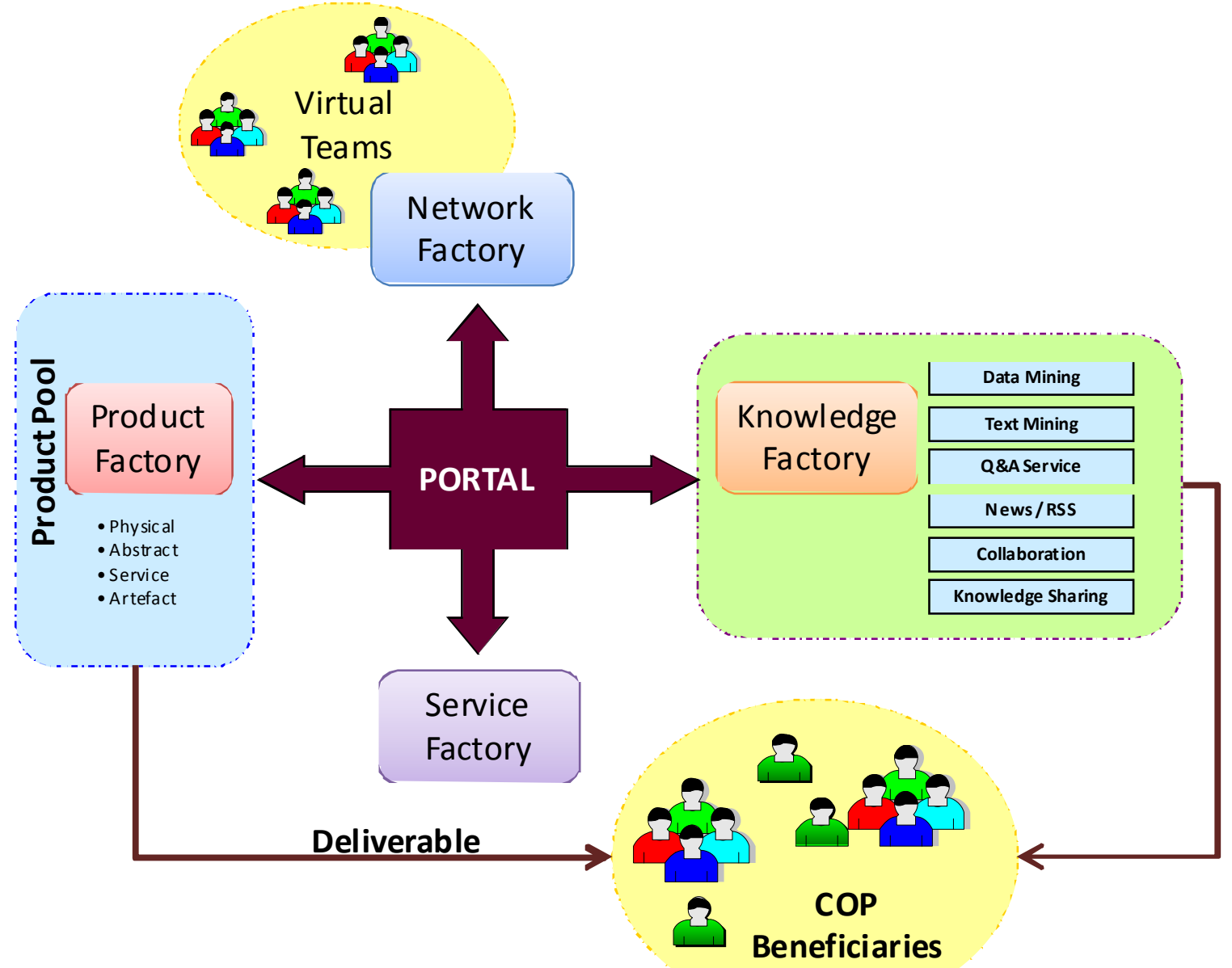

\section{TRUST / GOVERNACE}

Figure 2: Community Living Lab Factory Frame work 
Our proposed living lab framework as depicted in figure 3 consists of five key components to aid in the measurement of Living Lab Activity performance. The objective of the Product Factory $(\mathrm{PF})$ is to apply factory thinking to the development of a "product": physical, abstract, a service, artifact, etc. The beneficiaries of these processes are the Communities of Practice.

\section{The Product Factory}

As the product factory represents the processes and activities involved to deliver and create products in various forms, the value chain of the product factory would be configured, aimed and honed at performance management issues.

Figure 3 represent the processes and work flow for the performance management and value chain activities in the Product Factory.

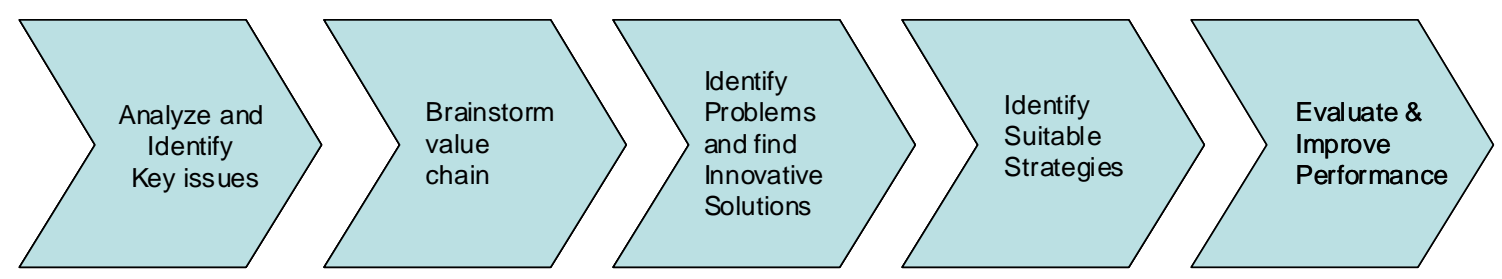

Figure 3: Processes and work flow for the Product Factory

The objective of the PF is to apply factory thinking to the development of a "product": physical, abstract, a service, artefact. Etc. The process starts with grounded theory thinking, identify and analyse key issues and find all the role players and create partnerships, using a bottom up collaborative thinking approach.

The second process use value chain thinking to analyse and brainstorm the value chains. The idea is to frame an action research environment which can assist new entrants to participate effectively.

The third process supports the Identification of problems and finding Innovative solutions. Strategic thinking is used to identify resource limitations and competitive weaknesses and find innovative solutions based on innovative thinking.

The fourth process supports the identification of suitable strategies. Systems' thinking based on means ends analysis, SWOT (SWOT represents the first letter in Strengths, Weaknesses, Opportunities and Threads) is applied to create innovative strategies and draw conclusions about the businesses current status and new market opportunities connected to its value chain and competitive analys is. Find out what are the changes needed to reach stated objectives and action plans.

The fourth process supports the product design. Systems' thinking is the foundation for understanding the interrelationships within the product design workflow, which are responsible for the manner in which factories operate. Operational research is used to optimize the operational processes.

The last process support the evaluation and improvement of the product performance, it measure how well the strategies are working in terms of trends in market share, customer and partner relationships, profit margins, quality and much other continuous improvements of value chains and innovative activities. Product performance management focuses on monitoring and managing the performance of the product using tools to detect, diagnose, remedy and report on performance issues to ensure that application performance meets or exceeds end-users' and businesses' expectations. 


\section{Network Factory (NF)}

The network factory helps to find people that you the community need. The primary objective of the networking factory is to establish a platform for the engagement of various role-players within the LL. The network factory therefore is to network various communities of practice members and stakeholders into various virtual teams. Community of Practice (COP) as described by Etienne Wenger is a community that comprise of a group of people with a shared interest that collaborates in a social network. This community will develop the ir own understanding among themselves of what their practice is all about. Learning takes place by their participation with each other. It also supports various types of filtering to connect role-players dynamically using technologies like Email, B logs, Co-spaces and internet conferencing help in creating networks.

Figure 4 represent the processes and work flow for the Network Factory.

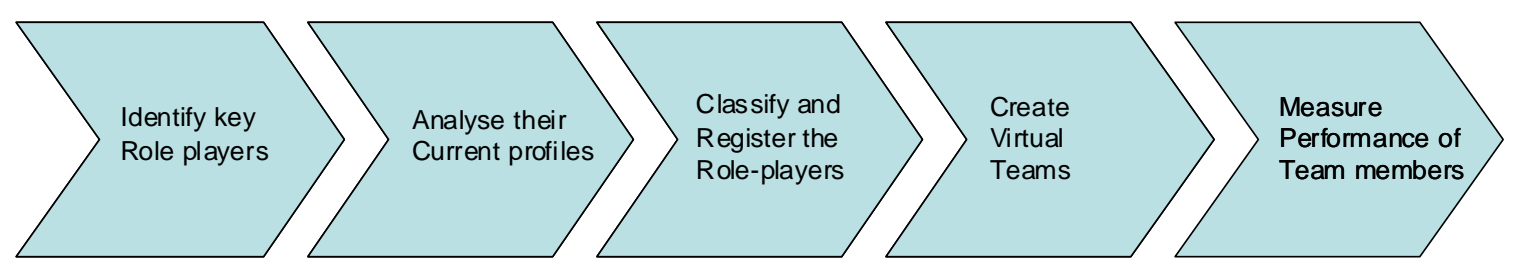

Figure 4: Processes and work flow for the Network Factory

Identify key role players is the first process connected to the network factory. It is very important to take the human factors into account with the creation and use of knowledge networks, Key players in the knowledge domain needs to be identified; we need to design programs and learning environments to help us identify and rate role players.

Analyzing role players current profiles is the second process connected to the network factory. The objectives of this process are to find out who is working on what and what their experiences are. A critical resource is the skills that role players bring to the party.

Classification and registering of the role players is the third process connected to the network factory. Role players are classified according to knowledge, roles, skills, abilities and preferences.

The next process supports the creation of virtual teams. This process helps to automate the selection and construction of teams based on the matching of project/research requirements with profiles.

Measure performance of team members is the last process connected to the factory process.

\section{Knowledge Factory (KF)}

The knowledge factory creates a dynamic set of Knowledge Objects implementing a Question and Answer Extrapolation tool (QAET). The QAET is build upon the utilization of questions in order to create reusable know ledge objects. The primary purpose of the QAET is in the management of user requests, and the formation of knowledge objects. We define a knowledge object $(\mathrm{KO})$ as any artifacts that could be implemented by a knowledge seeker in order to learn or expand the user's current knowledge regarding the specific search topic. KO's can take on a variety of formats, ranging from digital media to WEB 2.0 mashed objects. All KO's utilized are stored and managed in a Knowledge Object Repository, which is in essence a semantic web cataloguing system. Figure 5 represent the processes and work flow for the Knowledge Factory. 


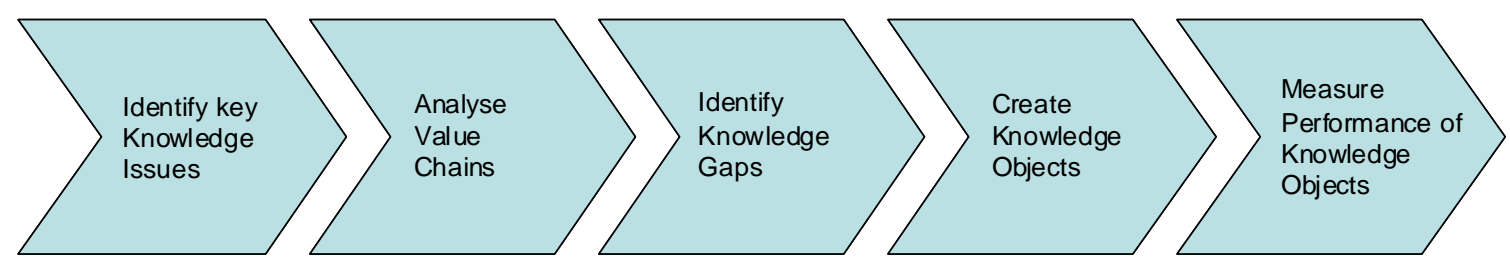

Figure 5: Processes and work flow for the Knowledge Factory

The first process supports the Identification of key know ledge issues.

Discovery and grounded theory thinking is used to find out what are the drivers, methodologies, metrics, processes and systems needed to manage knowledge and to develop human capital in the problem environment. Issues needs to be analyzed precisely and specifically and must lead to actions.

The second process supports the creation of value chains. Holistic value chain thinking, from the beginning to the end, is applied to all the learning objects, in order to understand their innovation potential against the current user community requirements.

The third process supports the Identification of knowledge gaps. Strategic thinking is used to compare the knowledge repository with current and feature needs, in order to determine the gaps, and set up strategies and action plans.

The fourth process is supporting the creation of knowledge objects. Process thinking is used to guide the creation of the needed knowledge objects. A systems thinking approach is used for know ledge management the creation of know ledge objects, knowledge management and the creation of knowledge objects to support a holistic improvement approach, through learning and common understanding.

The last process is supporting the performance measurement of knowledge objects. Performance thinking is used to analyze know ledge usage patterns for suitability and relevance and make adjustments if needed.

\section{Services Factory (SF)}

The services factory produces all the web services needed in order for the living lab to function. It included resource planning, Information, business and communication, and know ledge support and analytical services. A factory thinking approach supports the thinking processes behind the design of services. Complex inter organizational intelligent services depends on complex workflow architectural, real-time, risk and software maturity thinking. Services are used and activated by people using systems and business intelligence. Figure 6 represent the processes and work flow for the Services Factory.

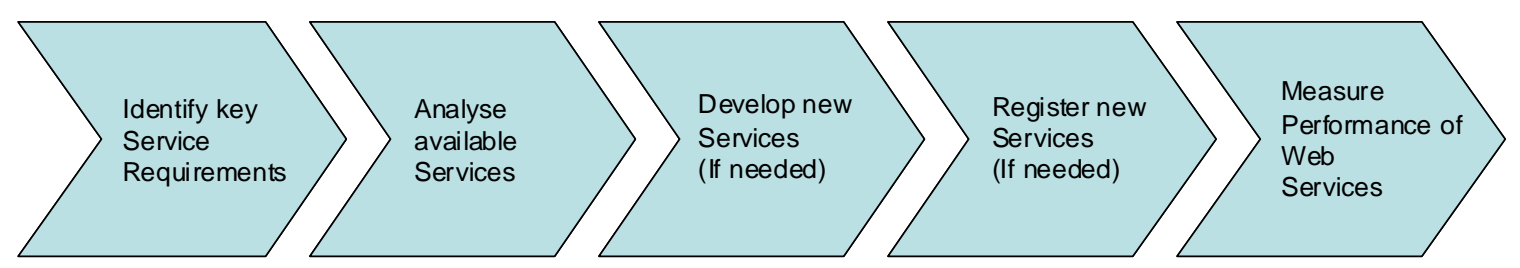

Figure 6: Processes and work flow for the Service Factory 
The first process supports the analysis of key service requirements. Discovery and process thinking supports the thinking processes in this environment to apply business process modeling to identify key service requirements.

The second process supports the identification of standard service building blocks. Discovery thinking was used to find this needed services building blocks. Value thinking is needed to improve value creation services with internal and external service providers

The third process supports the Identification of key services. Process thinking was used to orchestrate smaller services into bigger services or allow for the development of user domain specific services.

The fourth process supports the registration and publishing of new service (If needed), using standard tools and methodologies. Collaborative thinking supports sharing and joint construction of services.

The last process supports the performance management of web services. The performance of the services utilized is measured in terms of standard methodologies, tools and practice. Performance thinking is the driver behind this process. Control thinking (feedback systems) controlling levels of efficiency and affectivity a major thought process, by performance improvement.

\section{Living Labs in the South African Context}

The researchers are of the opinion that the true definition and purpose of a living lab within the South African context of rural area development encapsulates more than what is presented in the textual definitions. We regard and see a Living Lab as: A real-time experimental environment that enables different role players with some or other common interest within a domain to collaborate in the use and development of innovative ideas to solve current and real world problems in a unique and integrated way.

One of the main deliverables in our opinion within a living lab is that of an artifact which has been produced via a product factory.

We foresee that a critical success factor of a living lab is that of constant collaboration between all the various stakeholders which include the learners as well as the lecturer's potential employers and external stakeholders such as the government.

Mulder et al. (2008, pp. 7-8) highlighted that within the South African Rural context Living Labs will provide community based solutions that will be scalable and replicable on the African continent. Users play significant roles by identifying needs and formulating demands, thereby shaping emerging applications through processes of participatory design. To remain effective, the Living Lab must encourage and promote close interactions between the developers and users of technology. The Living Lab will encourage public/private/citizen participation as a catalyst for economic growth through entrepreneurship and new ventures in business.

\section{Community Living Lab Framework (ComLL)}

Figure 7 presents the framework of the Community Living Lab (ComLL) Lab in the South African context. The LL framework is based on the utilization of standard IC technologies i.e. ontology's, data mining, co spaces, semantic web, and Service Object Architectures, etc. The ComLL framework is based on applying principals like collective intelligence, event driven processes based on a multi- disciplinary approach. 
The primary objectives of the ComLL are to facilitate and support the follow ing pillar activities:

- To create a platform for learning,

- Allow for experimentation,

- Support collaboration, and virtualization

- Using an action research approach

The activities listed above are supported and facilitated via a portal by the various factories as supplied in Figure 2.

These objectives are towards the optimization of value chains which are based on value chain principles for the ultimate e-commerce vendor.

The intended application of these ComLL may incorporate a broad range of domains such as:

- Education (All sectors)

- Emergent Farmers

- Governmental Service Departments such as (Munic ipalities)

- Incubators for Software and Innovative Solutions

- Poverty alleviation

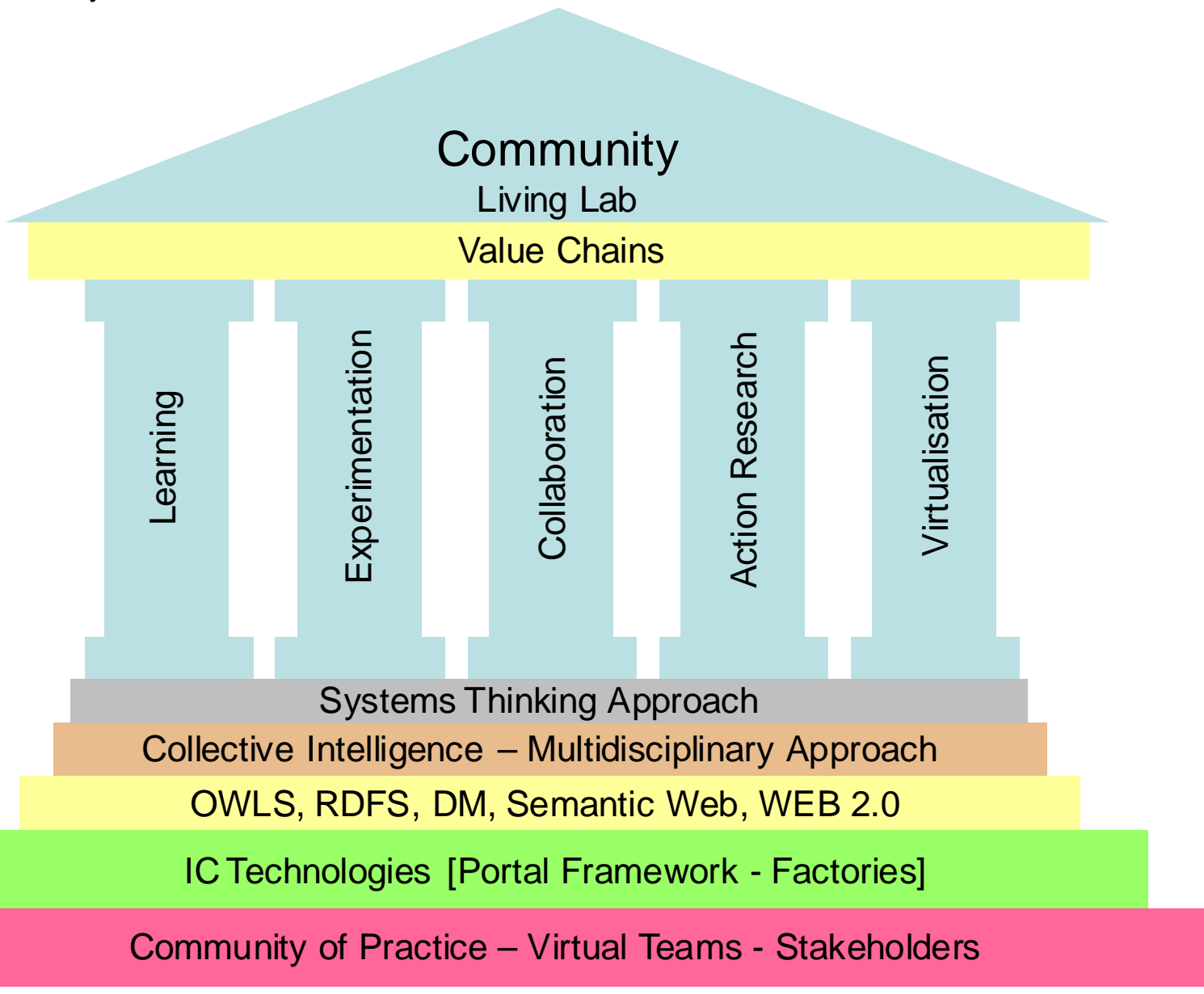

Figure 7: Community Living-Lab Conceptual Frame work (ComLL) 
It is important to state that there will be a definite overlap in some or all of the activities of each of the applicable areas for support in the domains as listed above. Many of these domains may face similar problems and challenges.

Today many research efforts are placed on the investigation of current Web 2.0 technologies. One such area is in the role out of collaborative learning and experimental environments. The Web 2.0 as a technology has proven itself as sustainable and viable through services such as Flickr, Youtube, Facebook or other social bookmarking sites like Digg and Delicio.us. Another prime example of an emerging Web 2.0 technology would be Wikipedia.

The researchers are of the opinion that current WEB 2.0 technologies are well suited for use within the CommLL. Internet applications like Face-book, Google Earth, Second Life and Wikipedia are all supportive evidence that it is possible to establish internet based systems and collaborative environments to enable $\mathrm{CoP}$ to jointly create valuable products, services, artefacts and know ledge objects in a Living Lab especially in a community living lab. Figure 8 highlights the position of some of the envisaged WEB 2.0 technologies into the LL factory framework as part of the Knowledge Factory.

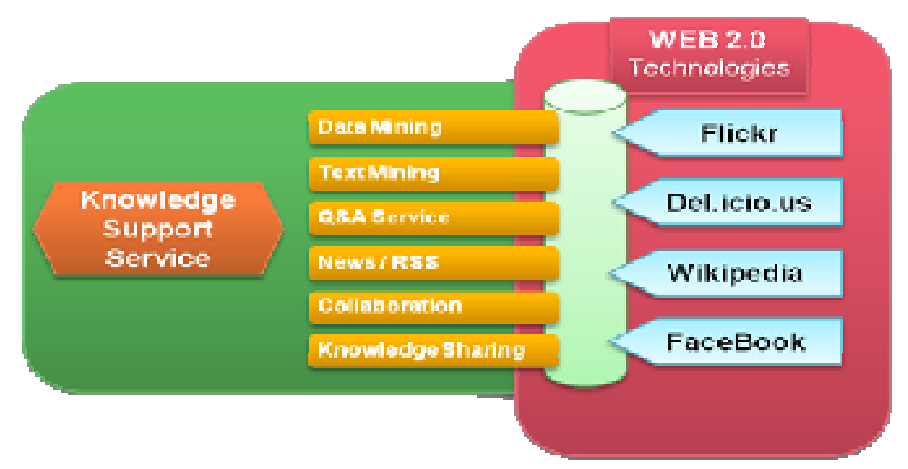

Figure 8: Location of Web 2.0 technologies in a Living Lab

\section{Community Living Labs: South African Case Studies}

The following section provides insight on the role-out and establis hment of two ComLL within South Africa. The establishment and development of these LL's are based on the two frameworks provided. The researchers are of the opinion that although the two LL are still at developmental phase, the overwhelming positive response shown by initial engagements with the communities will deem the projects successful.

\section{Soshanguve Living Lab}

Soshanguve is a predominantly rural township within the City of Tshwane Metropolitan Municipality in South Africa. The name SOSHANGUVE is derived from the first letters of the four major tribes in the region: Sotho, Shangaan, Nguni and Venda. The City of Tshwane Metropolitan Municipality within the Gauteng province covers an extensive geographic area (3200 sq. km), stretching for almost $60 \mathrm{~km}$ east/west and $70 \mathrm{~km}$ north/south. The greater municipal area is inhabited by approximately 1.5 million people. Rural and emergent townships such as Soshanguve are places where people suffer from poverty and living conditions are not always easy. (MyAbod, 2006). 
As part of the Tshwane University of Technology's (TUT) commitment to aid in the alleviation of poverty and to aid in the development the Faculty of ICT are relocating to the Soshanguve South campus of TUT. The interventions planned by the TUT for the Soshanguve South Campus fit well within the Governments development framework for without the relevant innovation and skills development the proposed economic acceleration cannot be sustained. TUT intends to develop skills, from the critical and scarce (e.g. information technology) to the more common areas, such as marketing and tourism, within the communities in which it operates. Therefore ICT tools, community tools such as businesses, research and development and the skills of Tshwane University of Technology will be combined to create a comprehensive community development process with the purpose of improving and innovating through the constant assessment of deliverables. TUT see the development of the ir campuses as Centres of Excellence to provide leadership, synchronization and integration of diverse frameworks and specialist services; in order to build new industrial and technological capabilities, strengthen existing ones, and also lay a solid platform for enhanced competitiveness of relevant sectors. The aim is to provide human skills with higher education qualifications fit for purpose and fit for market. The faculty of ICT is intensely involved in the establishment of the Soshanguve Living Lab, (SLL) (Turowiec \& Zaaiman, 2007).

\section{Venda Living Lab}

The University of Venda in Thohoyandou, Limpopo Province of South Africa has started with the Venda Living Lab, which focus on developing a software base to support the development activities especially in the fields of Health and Agriculture and small business development. The University is focusing on supporting the Tshivhase Chiefdom in Venda, the local Correctional Services to develop 3000 inmates, Regional Munic ipal Authority and the Province of Limpopo in development and capacity building, job creation and sustainable development. Many possibilities are currently under consideration like exotic bird breeding, fish breeding, and research on bananas, guavas, litchis, nuts, avocados, mangos and plantations.

\section{Conclusion}

Living Labs are systems consisting of tools, processes and methodologies for the creation of innovation environments focusing on real life user communities. The Living Lab approach is a natural tool for learning, experimentation and research for the implementation of large scale collaborative product/service performance improvement opportunities for organizations. From a community of practice perspective Living Labs offer a research, "think-tank" and innovation platform which can help them to apply user-driven innovation practices. Living labs can help them to optimize their value chains and obtain better values for their clients.

Thinking frameworks are the eco-system architecture behind the design of innovative community support environments. Systems' thinking is, more than anything else, a mindset for understanding how things work. It is a perspective for going beyond events, to looking for patterns of behaviour, to seeking underlying systemic interrelationships which are responsible for the patterns of behaviour and the events.

This paper provided new insights into the various thinking processes that are envis ioned within a living lab environment. Now more than ever innovative ideas and solutions that have been designed with a bottom- up approach are needed, in order to solve South Africa's unique spectrum of problems. The researchers believe that the development of future LL's based on the ComLL framework provided in this paper, which is facilitated by the various product factories via a portal environment holds the key to all the envisaged successes and perceived benefits. 


\section{References}

Abowd, D., Atkeson, G., Bobick, F., Essa, A., Macintyre, B., Mynatt, D., \& Starner, E. (2000). Living laboratories: The future computing environments group at the Georgia Institute of Technology. Retrieved 9 August 2008 from www.gvu.gatech.edu/fce

Barnes, M. (2004). Value chain guidebook: A process for value chain development. Agriculture and Food Council of Alberta. Value Chain Initiative. Alberta, Canada.

Boronowsky, M., Herzog, O., Knackfub, B. \& Lawo, M. (2006). Wearable computing - An approach for living labs. Retrieved 10 September 2007 from www.wearitatwork.com

Buitendag, A. A. K., \& van der Walt, J. S. (2007). Presenting a knowledge support portlet via commun ity learning areas to act as an innovation catalyst for rural communities of practice. 5th International Conference on Entrepreneurship and Innovation (Conference Proceedings) Pretoria, South Africa.

CoreLabs. (2007) Bu ild ing sustainable competitiveness living labs roadmap 2007-2010. Recommendations on networked systems for open user-driven research, development and innovation. Retrieved 9 February 2009 from http://www.amicommunities.eu/pub/bscw.cgi/d310714/Living\%20Lab\%20Roadmap\% 202007-2010.pdf

Følstad, A. (2008). Living labs for innovation and development of in formation and communication technology: A literature revie w. The Electronic Journal for Virtual Organizations and Networks, 10, "Special Issue on Living Labs." Retrieved February 10, 2009 fro $\mathrm{m}$ http://www.ejov.org/

Leon, P., Eriksson, M., Balasubramaniam, S., \& Donnelly, W. (2006). Creating a distributed mobile networking testbed environment - through the living labs approach. Retrieved 1 November 2007 from $\underline{\text { www.ieee.com }}$

Lacasa, P., Martinez, R., Mendez, L., \& Cortes, S. (2007). Classrooms as "living labs": The role of commercial games. Retrieved 20 Septe mber 2007 from www.uah.es

Lama, N., \& Orig in, A. (2006). Innovation ECOSYSTEMS: Services engineering \& living labs a dream to drive innovation? Retrieved 1 September 2007 from www.atosorigin.com

Living Labs Europe. (2007). Retrieved 10 September 2007 from www.living labs-europe.com

Mulder, I., Bohle, W., Boshomane, S., Morris, C., Tempelman, H., \& Velthausz, D. (2008). Real-world innovation in rural South Africa. The Electronic Journal for Virtual Organizations and Networks. 10, "Special Is sue on Living Labs." Retrieved February 10, 2009 fro $\mathrm{m}$ http://www.e jov.org/

MyAbod.com(2008) MyAbout. Townships like Soshanguve. Advanced Design Innovation LLC. Retrieved 29 May 2008 from http://www.myabod.com/location

Nu mprasertchai, S., \& Igel, B. (2005) Managing knowledge through collaboration: Multiple case studies of managing research in university laboratories in Thailand. Retrieved 15 January 2005 from http://www.sciencedirect.com

Oliveira, A., Fradinho, E., \& Caires, R. (2006). From a successful regional information society strategy to an advanced living lab in mobile technologies and services. Retrieved 1 Nove mber 2007 from $\underline{\text { www.ieee.com }}$

Pallot, M. (2006): Living labs. Retrieved 10 October 2007 fro m: www.ami-communities.eu

Pretorius, P., \& van der Walt, J. S. (2007) Living lab as an innovative tool in education. Proceedings of the 5th International Conference on Entrepreneurship and Innovation, Pretoria, South Africa.

SystemsThinking.org (2009) Mental model musings. Retrieved 9 February 2009 from $\underline{\text { http://www.systems- }}$ thinking.org

Thompson, A. A, Strickland, A. J., \& Gamble, J. E. (2007). Crafting and executing strategy (15th ed.). McGraw- Hill.

Turowiec, A., \& Zaaiman, J. J. (2006). Soshanguve living lab (Strategy Document - Pambili - TUT for Tshwane North 2008 - 2010) Pretoria, South Africa. 
Wenger, E. (1998). Communities of practice: Learning as a social system. The Systems Thinker, 9(5). Waltham, MA, USA: Pegasus Communications.

\section{Biographies}

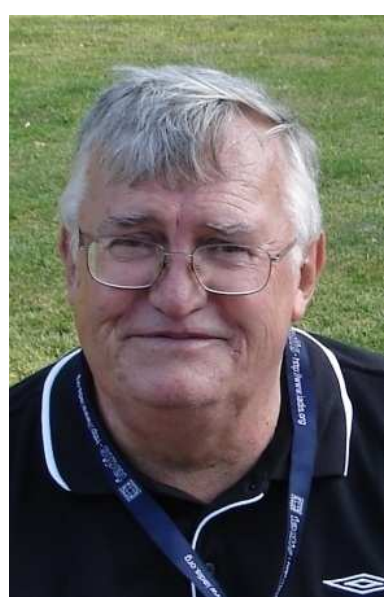

Prof. Jacobus (Potjie) van der Walt has been intensively involved in ICT research over the past 27 years at the Tshwane University of Technology (TUT). His core research interests currently pertain into the study of emergent community-oriented ICT support, with specific reference to portal based applications for emergent farmers. He has successfully supervised numerous post graduate students. He was also one of the first academia in South Africa to publish a paper regarding community oriented Living Labs. He also started the Soshanguve LL initiative.

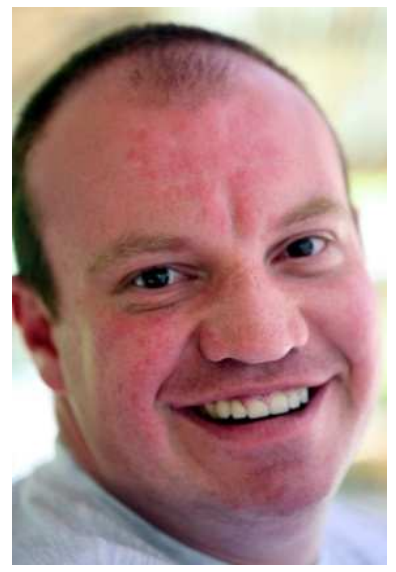

Bertie B uite ndag is currently enrolled for his D-Tech in Enterprise Application Development at TUT under the supervision of Prof JS van der Walt. His core research area includes ICT Knowledge support for emergent farmers and Living Labs. Other areas of interest include the: Semantic Web, (WEB 3.0) and WEB 2.0, and ICT's for community upliftment.

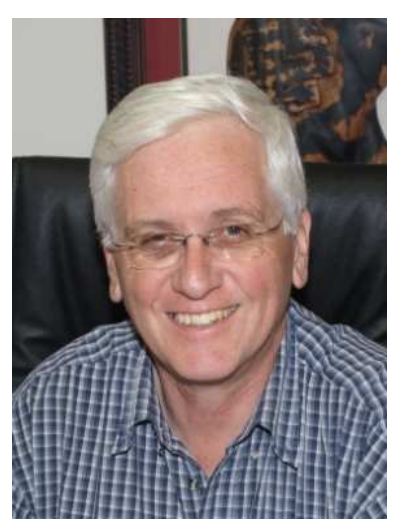

Dr Jannie Zaaiman is currently Deputy Vice Chancellor of the Venda University. His core interests and field of expertise is in the management field with specific reference to the Management of Change. He has played a significant role in the successful transformation of various South African institutions over the past few years, which include amongst others: SASOL, Telkom SA, and more recently the Faculty of ICT at TUT. He is one of the strong advocates and driving forces behind the envisaged establishment of the Venda Living Lab. 


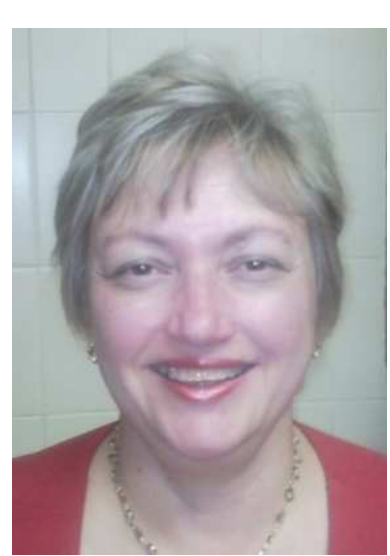

Joey Jansen van Vuuren is the current Research Group Leader of the Information warfare research group, division Defence Peace Safety and Security of the CSIR (Council for Scientific and Industrial Research). She is currently enrolled for her $\mathrm{PhD}$ under the supervision of Prof van der Walt and Dr Zaaiman. Her areas of interest and expertise reside in the Management Science field, Information Security and Living Labs. 